\title{
IDENTIFICATION AND MAPPING OF TREE SPECIES IN URBAN AREAS USING WORLDVIEW-2 IMAGERY
}

\author{
Y. T. Mustafa ${ }^{a}$, H. N. Habeeb ${ }^{\mathrm{b}}$, A. Stein ${ }^{\mathrm{c}}$, F. Y. Sulaiman ${ }^{\mathrm{b}}$ \\ ${ }^{\text {a }}$ Faculty of Science, University of Zakho, Kurdistan Region of Iraq - yaseen.mustafa@uoz.ac \\ b Directorate of Forestry, Duhok, Kurdistan Region of Iraq - (hindavberwary@gmail.com, faroqmziry@gmail.com) \\ ${ }^{\mathrm{c}}$ Faculty of Geo-Information Science and Earth Observation (ITC), University of Twente, \\ 7500 AE Enschede, The Netherlands - a.stein@utwente.nl
}

KEY WORDS: Urban tree species, Supervised classification, VHR imagery, Kurdistan Region of Iraq

\begin{abstract}
:
Monitoring and mapping of urban trees are essential to provide urban forestry authorities with timely and consistent information. Modern techniques increasingly facilitate these tasks, but require the development of semi-automatic tree detection and classification methods. In this article, we propose an approach to delineate and map the crown of 15 tree species in the city of Duhok, Kurdistan Region of Iraq using WorldView-2 (WV-2) imagery. A tree crown object is identified first and is subsequently delineated as an image object (IO) using vegetation indices and texture measurements. Next, three classification methods: Maximum Likelihood, Neural Network, and Support Vector Machine were used to classify IOs using selected IO features. The best results are obtained with Support Vector Machine classification that gives the best map of urban tree species in Duhok. The overall accuracy was between $60.93 \%$ to $88.92 \%$ and $\kappa$-coefficient was between 0.57 to 0.75 . We conclude that fifteen tree species were identified and mapped at a satisfactory accuracy in urban areas of this study.
\end{abstract}

\section{ITRODUCTION}

An interesting and prospective way to alleviate the negative impact of urban growth and its implications is by means of managing urban forests and urban trees in metropolitan areas. They are regarded as key elements to improve the living conditions of the urban dwellers and to diminish polluting effects following human activities (Song, 2005; Yang, 2012).

Trees and green spaces help cleaning the air by removing pollutants during the transpiration process. They can alleviate the urban heat island problem effect that is common to large cities by lowering the city temperatures by means of transpiration, shading and heat absorption ( $\mathrm{Pu}$ and Landry, 2012; Weng et al., 2004). Due to these effects, a growing interest has been observed among city planners and stake holders for a better control, planning and management of planting and conservation of urban trees. In order to make this effective, the current state of urban trees has to be mapped.

A traditional technique of obtaining the information about urban trees canopy and species composition is the field surveys. Field surveys, however, are time-consuming, expensive and usually cannot provide complete coverage of large areas. An alternative way is by using satellite remote sensing images, due to their advantage of being able to obtain data for a large area simultaneously. To produce an accurate map for individual tree species and tree canopy, however, high spatial and spectral resolution satellite imagery is required especially in highly heterogeneous urban environment. A very high resolution (VHR) satellite imagery has shown to be a cost-effective alternative to field surveys for extracting individual tree crowns (Ardila et al., 2012). Moreover, accurate mapping of individual tree species and tree canopy using VHR satellite requires advanced algorithms and methodologies for analysis.

One possibility to do so, is to use an object-based image analysis (OBIA). OBIA techniques produce discrete regions or image objects (IOs) by means of image segmentation. IOs are more homogeneous in themselves than with nearby regions (e.g., a tree crown) and in this sense have an advantage over using individual pixels as a classification unit (Belgiu et al., 2014; Blaschke, 2010). Several studies based on mapping vegetation cover types and tree species composition have demonstrated the advantages of OBIA with VHR imagery as WV-2 (Ardila et al., 2011; Belgiu et al., 2014; Pu et al., 2011). Most of the researches so far, however, were carried out with a limited number of tree species in an urban area, most of which are not abundant in the Kurdistan Region of Iraq.

The focus of this study was to assess the utility of high spatial resolution WV-2 imagery for identifying and mapping urban tree species in this area, with particular attention to the Duhok city. To do so, the tree canopy was first isolated from non-tree cover using remove shadow technique, vegetation indices and texture measurements to create IOs from WV-2. Next, three classification algorithms (Maximum Likelihood, Neural Network, and Support Vector Machine) were applied to classify these IOs, and the classifier with the most accurate output was used for urban tree species mapping. In this way the best observation and monitoring method was identified.

\section{STUDY SITE AND DATA}

\subsection{Site description}

The city of Duhok is located in the north-western of Kurdistan

* Corresponding author 
Region of Iraq and is embraced by two chains of mountains, the Bekhair chain in the north and northeast, and the Zaiwa chain in the southeast (Figure 1). It thus has a linear shape. It covers approximately $104 \mathrm{~km}^{2}$ with an elevation of 430-450 m above the sea level. Two residential test sites were identified (Figure 1(c)). The first site is located in the central-north part of the city and covers approximately $788000 \mathrm{~m}^{2}$ (Figure 1(d)). The second site is located in the central-south part of the city and covers approximately $775800 \mathrm{~m}^{2}$ (Figure 1(e)). These sites were selected because of the presence of other vegetation surfaces (i.e. grasslands and shrubs), and because no a major change happened in these sites except for the natural tree growth which was confirmed after visiting the sites and consulting the municipality of Duhok. The sites contain 15 different tree species, namely: Pomegranate (Punica granatum), Grapes (Vitis spp.), Calabrain pine (Pinus brutia Tenore.), Common pear (Pyrus communis.), Common walnut (Juglans regia L.), Oriental plane (Platanus L.), Mulberry (Morus L.), Siberian apricot (Prunus armeniaca.), Chinaberry (Melia azedarach L.), Common fig (Ficus carica L.), Orange (Citrus sinensis (L.)), Eucalyptus (Eucalyptus obliqua), Olive (Olea europaea.), Mediterranean cypress (Cupressus sempervirens), Loquat (Eriobotrya japonica.).

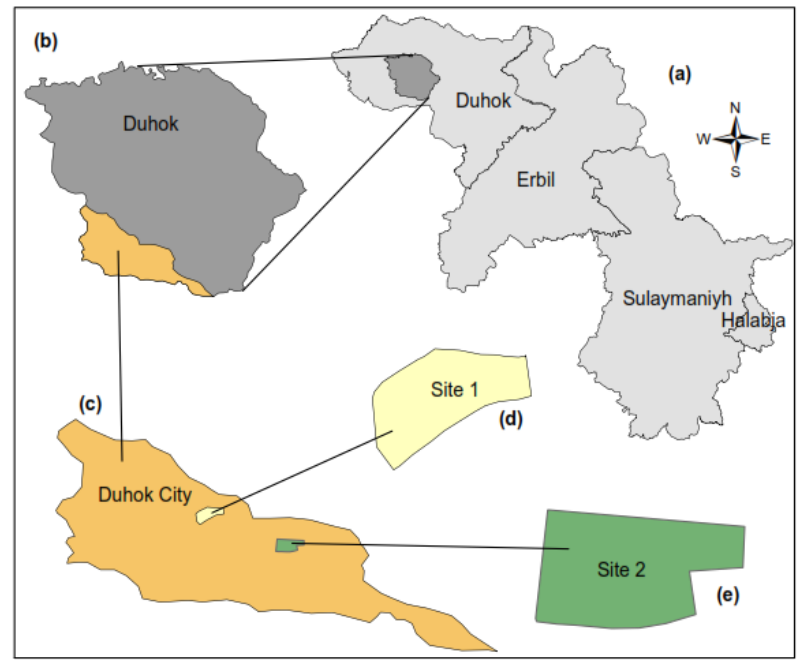

Figure 1: (a) Map of the Kurdistan region of Iraq, (b) Map of the Duhok district, (c) Map of the city of Duhok (d) Site 1

(e) Site 2 .

\subsection{Data}

The study is primarily based upon field data and WV-2 data.

2.2.1 Field data: The field data include the tree species name and their location (longitude, latitude, and altitude). During fieldwork carried out from 10 to 20 May 2014 a simple random sampling method is used to collect the required data for classification. This method is selected as it reportedly provides satisfactorial results (Congalton, 1988). False color composite images (NIR/Red/Green bands vs. R/G/B) of $\mathrm{WV}-2$ were brought to the field to directly locate and delineate tree species on the image for later use during training and validation. Trees have been categorized into two groups: main trees (4 species) and secondary trees (11 species). This distinction is made on basis of popularity of the trees and their abundance. Table 1 shows the number of samples of each group and trees for both training and validation purposes at both sites.

\begin{tabular}{|c|c|c|c|}
\hline \multicolumn{2}{|r|}{ Species } & Training & Validation \\
\hline \multirow{4}{*}{ 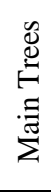 } & Eriobotrya japonica. & 57 & 27 \\
\hline & Ficus carica $L$. & 100 & 44 \\
\hline & Eucalyptus obliqua & 48 & 21 \\
\hline & Pinus brutia Tenore & 50 & 25 \\
\hline \multirow{11}{*}{ 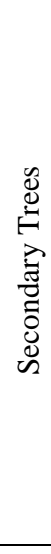 } & Citrus sinensis $(L)$. & 61 & 26 \\
\hline & Cupressus sempervirens & 30 & 15 \\
\hline & Juglans regia $L$ & 25 & 13 \\
\hline & Melia azedarach $L$ & 39 & 16 \\
\hline & Morus $L$ & 35 & 14 \\
\hline & Olea europaea & 39 & 16 \\
\hline & Platanus. & 20 & 11 \\
\hline & Prunus armeniaca. & 21 & 11 \\
\hline & Punica granatum. & 18 & 10 \\
\hline & Pyrus communis & 22 & 11 \\
\hline & Vitis spp & 33 & 14 \\
\hline \multicolumn{2}{|c|}{ Total } & 598 & 274 \\
\hline
\end{tabular}

Table 1: A list of fifteen (main and secondary) tree species used in this study, split into training and validation samples.

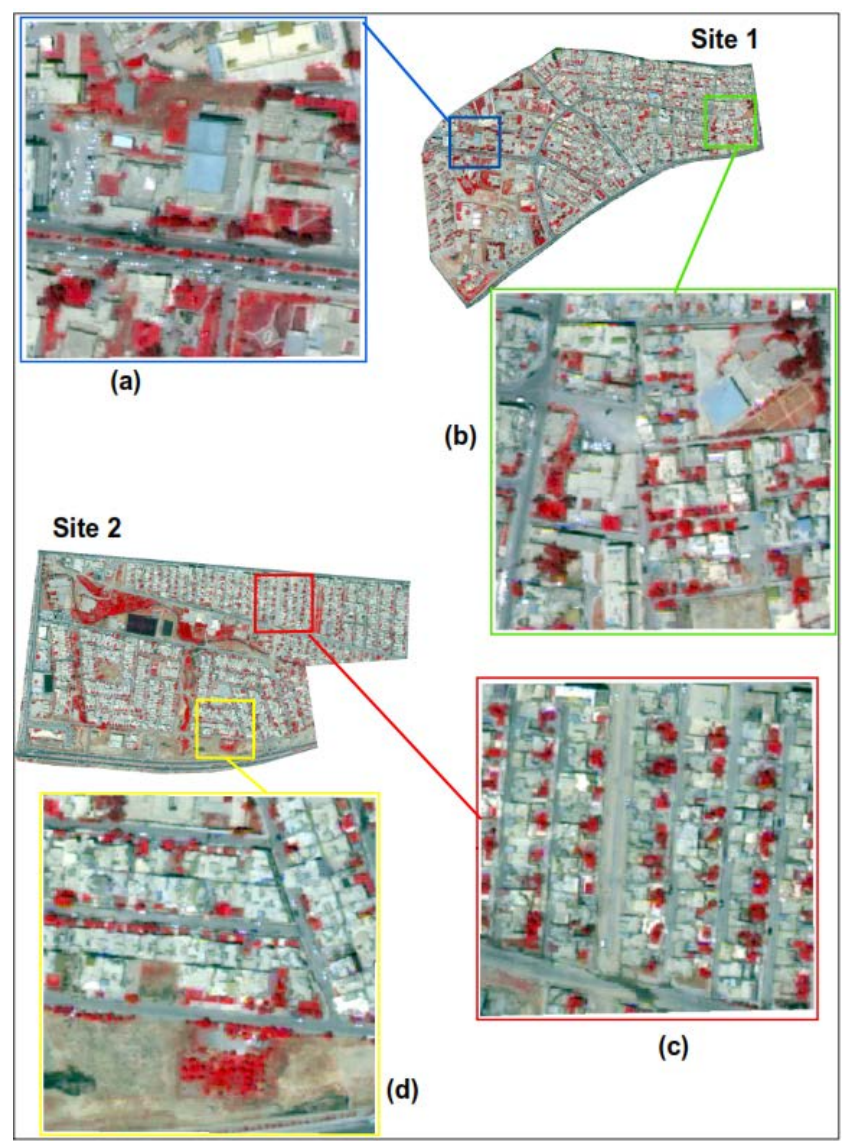

Figure 2: Four VHR samples from both sites: (a) Sample 1 (SP01) spared trees with grass land, (b) Sample 2 (SP02) low dense tree crowns without grass land, (c) Sample 3 (SP03) individual tree crowns, (d) Sample 4 (SP04) low dense tree crowns 
2.2.2 Satellite data: The WV-2 satellite is a unique satellite owned by Digital Globe that has a high spatial resolution, with eight spectral bands. It provides 1.85 m multispectral resolution and $46 \mathrm{~cm}$ panchromatic resolution imagery at Ground Sampling Distance (GSD) nadir and $770 \mathrm{~km}$ altitude (DigitalGlobe, 2009). The characteristics of WV-2 imagery that is used in this study is shown in Table 2. The study sites were covered by one WV-2 scene, acquired in June 2011. The image was pre-processed and orthorectified by the image distributor (DigitalGlobe, 2012).

\begin{tabular}{llll}
\hline $\begin{array}{l}\text { Band } \\
\text { no. }\end{array}$ & Colour & $\begin{array}{l}\text { Spectral } \\
\text { rang }(\mathrm{nm})\end{array}$ & $\begin{array}{l}\text { Spatial } \\
\text { resolution }(\mathrm{m})\end{array}$ \\
\hline 1 & Coastal blue & $400-450$ & 1.85 \\
2 & Blue & $450-510$ & 1.85 \\
3 & Green & $510-580$ & 1.85 \\
4 & Yellow & $585-625$ & 1.85 \\
5 & Red & $630-690$ & 1.85 \\
6 & Red-Edge & $705-745$ & 1.85 \\
7 & NIR1 & $770-895$ & 1.85 \\
8 & NIR $_{2}$ & $860-1040$ & 1.85 \\
& Pan & $460-800$ & 0.46 \\
\hline
\end{tabular}

Table 2: Characteristics of the WV-2 imagery.

\section{IMAGE OBJECT (IO) IDENTIFICATION \& MAPPING}

Figure 3 presents a diagram of the IO identification and mapping workflow.

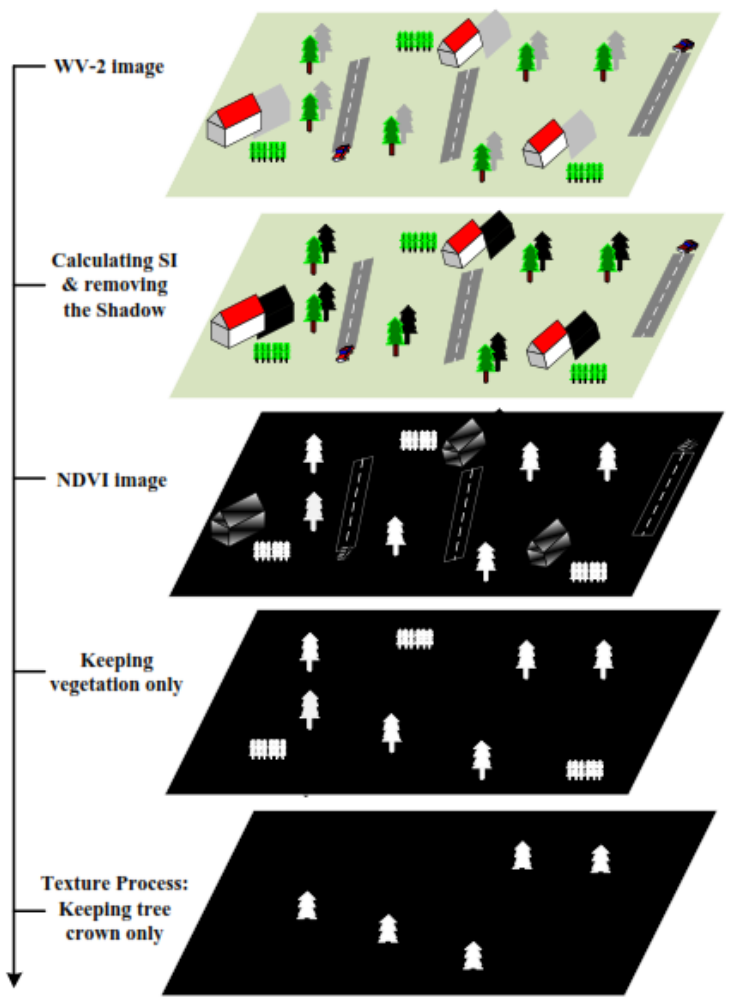

Figure 3: Schematic representation of a tree crown identification in an urban area.

\subsection{Shadow Index (SI)}

The presence of shadows of the trees is a major problem during classification. In order to remove shadows, the following equation was proposed:

$$
\mathrm{SI}=\sqrt{(256-\mathrm{Red})(256-\mathrm{NIR})}
$$

where NIR and Red are the near infrared and the Redreflectance bands, expressed in WV-2 by bands 7 and 5 , respectively. Areas identified as shadows were then masked out from the images.

\subsection{Normalized Difference Vegetation Index (NDVI)}

The object of interest (OI) in this study is the tree crown. Therefore, the ground was removed, including water, soil, and any non-vegetation objects by applying the following equation:

$$
\mathrm{NDVI}=\frac{\mathrm{NIR}-\mathrm{Red}}{\mathrm{NIR}+\text { Red }}
$$

where NIR and Red are the near infrared and Red-reflectance bands, respectively. Next, non-vegetation areas were masked out from the images.

\subsection{Texture}

To enhance the class separability between tree crowns and other vegetated surfaces such as shrubs and grasslands, a texture band was computed. The Grey-Level Co-occurrence Matrix (GLCM) (Haralick et al., 1973) is a commonly used texture measure in image classification that is applied in connection with VHR images (Ahmed et al., 2011; Kim et al., 2009). It contains the relative frequencies in which two neighbouring pixels (separated by distanced $d$ with angle $\theta$ ) occur on the digital image, one with grey-tone $i$ and the other with grey-tone $j$ (Marceau et al., 1990). After visually examining different GLCM texture measures, we found that homogeneity and entropy can effectively separate grass and trees. These statistical measures describe specific textural characteristics of the image (Haralick et al., 1973), where homogeneity refers to the smoothness of the surface while the entropy refers to the roughness of the surface such that a high value of entropy means a rough surface and vice versa. Both texture measures were calculated for the NIR band using $7 \times 7$ processing windows. The windows of $7 \times 7$ size were experimentally chosen to help reduce edge effects associated with large texture windows as it reported by (Ferro and Warner, 2002). They found that a minimum size window was needed for accurate surface feature recognition, and that the window size needed increased as spatial resolution increased until a threshold was reached, after which no further advantage was gained from larger windows. Moreover, the reason to select the NIR band was that it contained the largest range in spectral brightness values. We applied a threshold on the textural feature values and their values were chosen based on a trial and error. For example, a low homogeneity value and a high entropy value were used for detecting tree canopy, whereas a high value of homogeneity and low value of entropy were used for identifying grassland.

\subsection{IO Classification}

Among the conventional methods of classifying the multispectral imagery, three classifiers were selected for the performance test, namely the Maximum Likelihood (ML), Neural Network (NN), and Support Vector Machine (SVM) classifier. The ML classifier is based on a statistical decision criterion that assists in the classification of overlapping signatures, where pixels are assigned to the class of highest probability (Tso and Mather, 2009). The NN classifier comprises a number of simple processing units (nodes) which 
are linked by a weighted connection according to a specified architecture (Tso and Mather, 2009). It is an iterative process, such that the interconnecting weights of the network nodes are adjusted in an iterative fashion (Petropoulos et al., 2010), until some targeted minimal error is achieved between the desired output (the training classes) and actual output of the network.
Finally, the SVM classifier is a discriminating classifier, defined by a separating hyperplane. It is especially advantageous in the presence of heterogeneous classes for which only few training samples are available (Melgani and Bruzzone, 2004). The highest output accuracy among these three classifiers was used for selecting the best classifier for tree species mapping. (a)
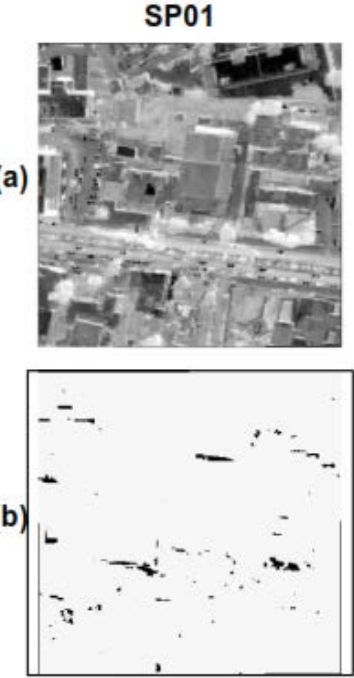

(c)

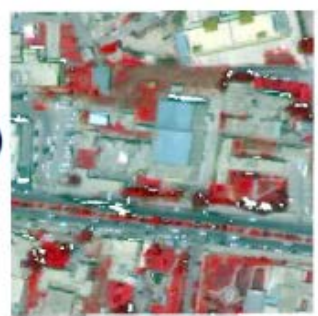

SP02
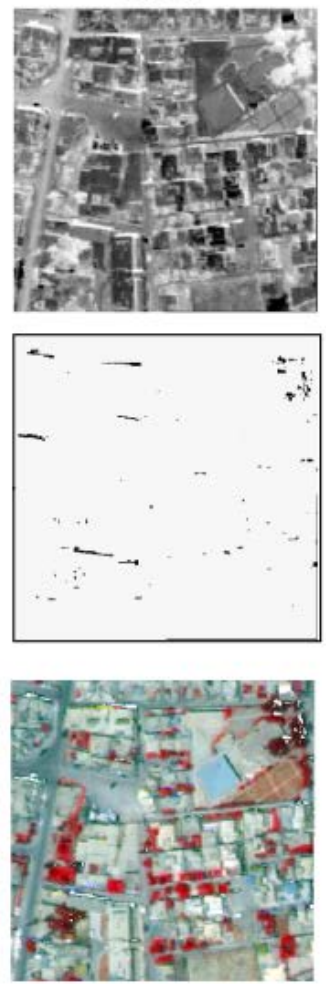

SP03
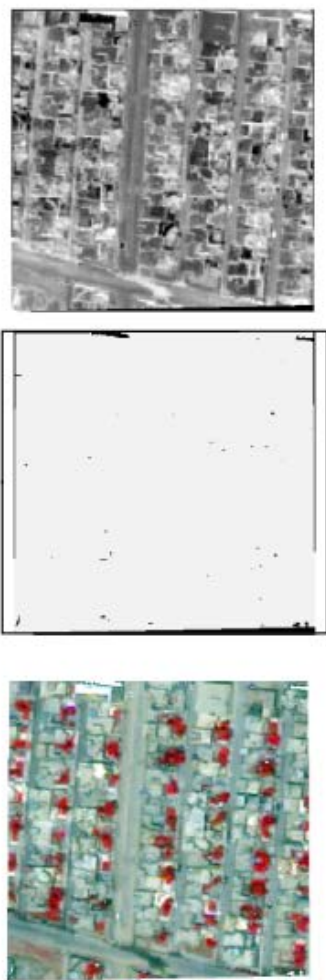

SP04
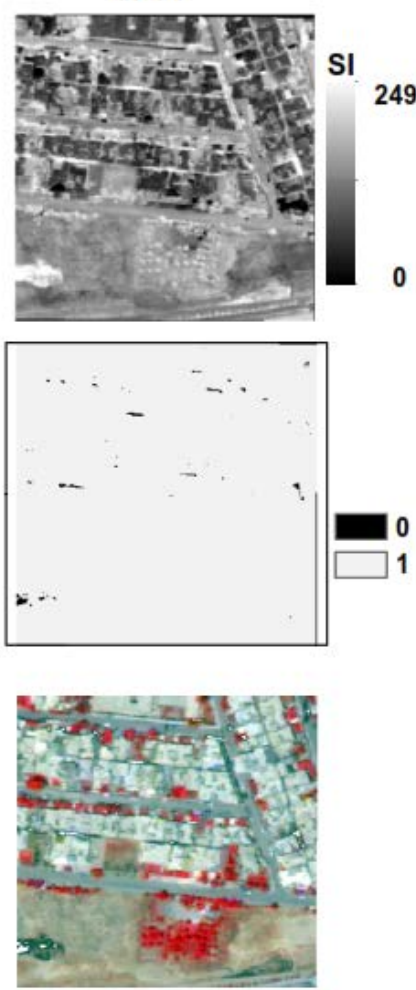

Figure 4: SI process of four VHR samples. (a) SI image, (b) SI mask, (c) Final output: image without shadow. SP01
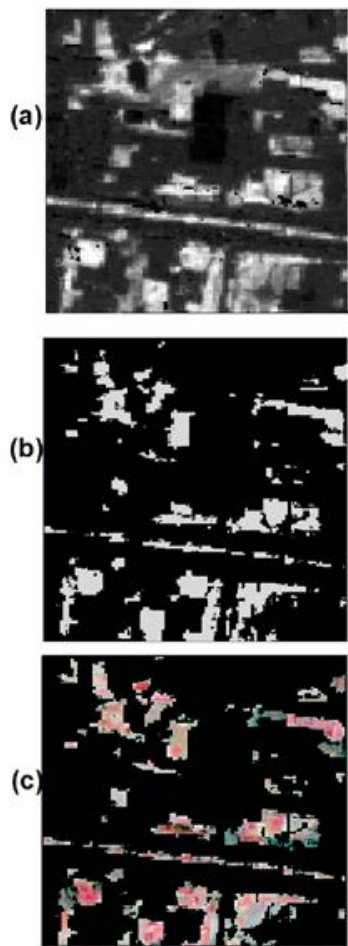

SP02
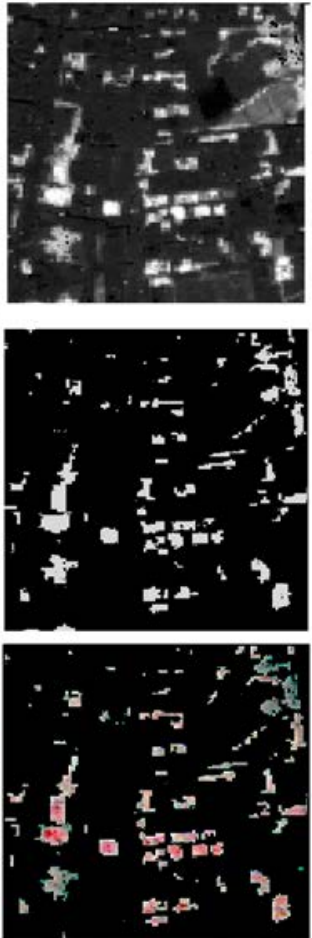
SP03
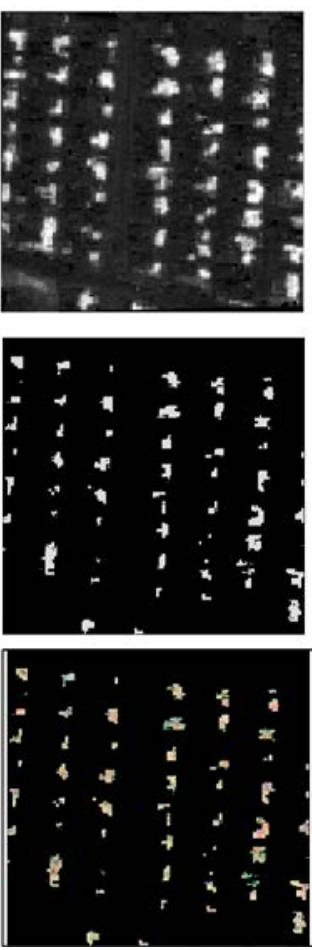

SP04
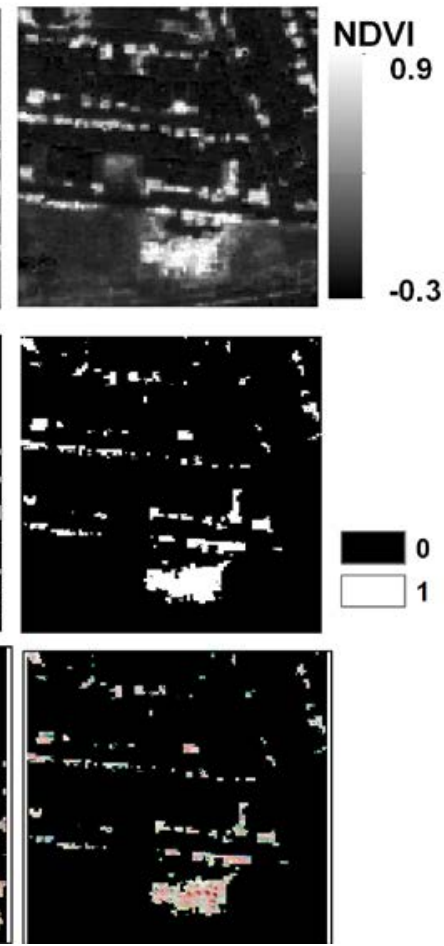

Figure 5: NDVI process of four VHR samples. (a) NDVI image, (b) NDVI mask,

(c) Final output: image with vegetation canopy only. 
(a)

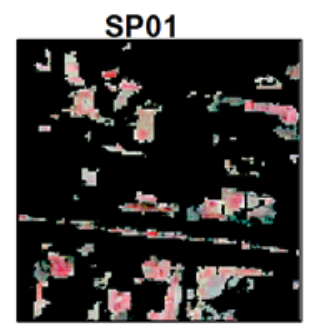

(b)

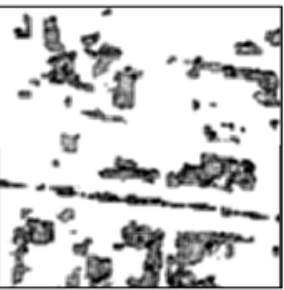

(c)

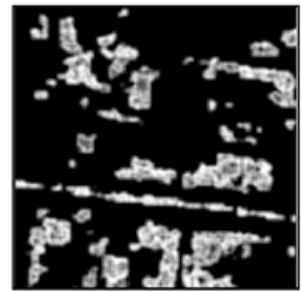

(d)

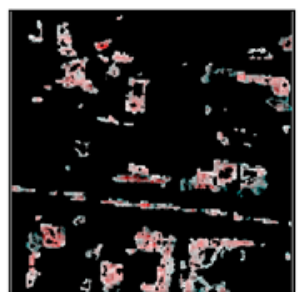

SP02
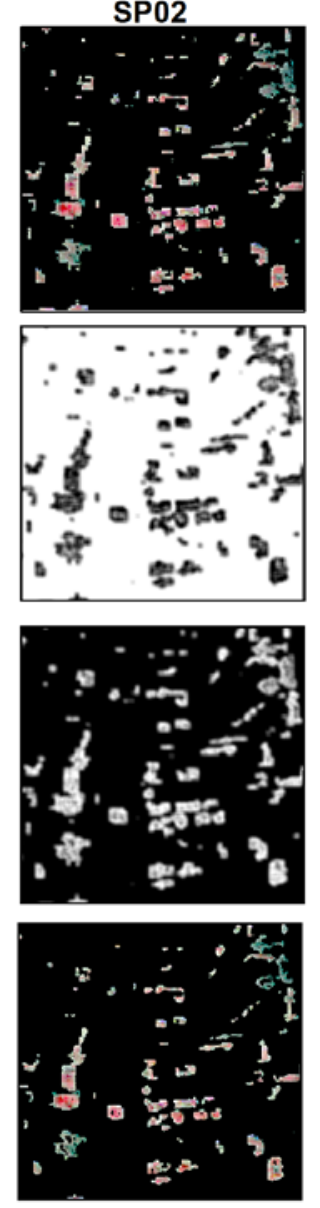
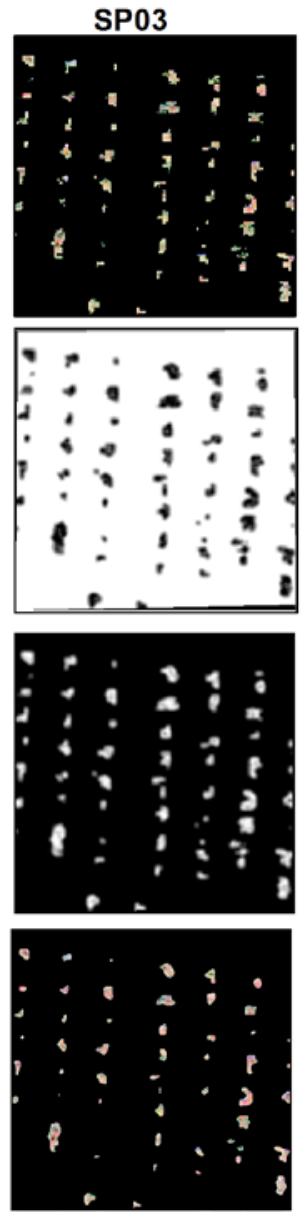
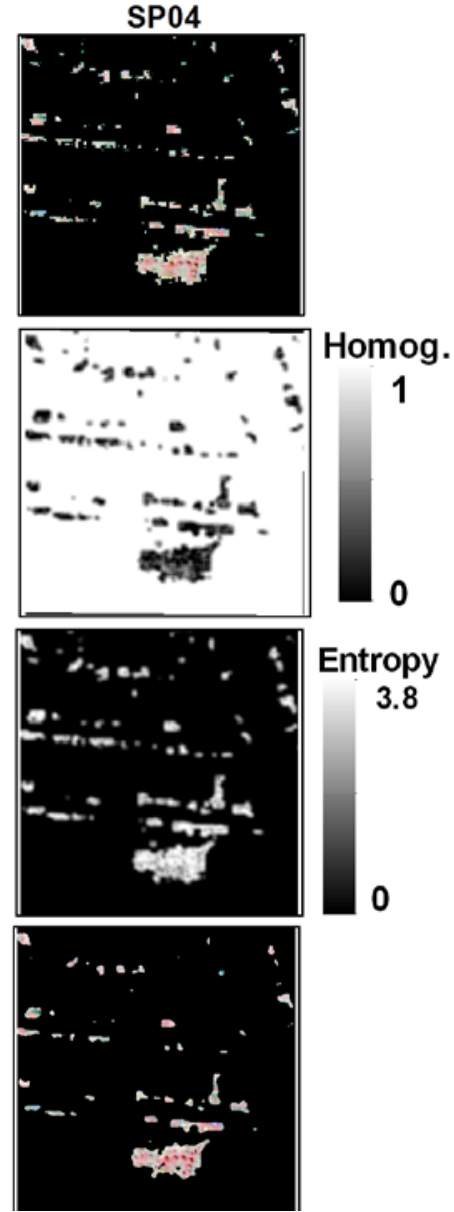

Figure 6: Texture process of four VHR samples. (a) Final output of NDVI process,

(b) homogeneity, (c) entropy, (d) Final output of Texture process.

\section{RESULTS AND DISCUSSION}

Following the workflow steps given in Figure 3, the method was tested on four different samples from the satellite image of both sites (two samples for each site) as shown in Figure 2. The images were chosen with the objective to capture different tree species and densities as well as different land use patterns.

Figure 4(a) shows the results for the SI image; by applying Equation 1, as the white area here represents the shadow area which is not a common way of having a shadow in black colour. After applying a threshold to the SI image, a binary image is created with the value 0 indicating the black area and the value 1 indicating the white area (Figure 4)(b). The threshold value for SI was determined experimentally, and in this study it was chosen to equal 228. The final output is shown in Figure 4(c) where evidently the shaded area has been removed and the image turns into an image without shadow. In this way it was possible to get rid of the confusing spectral problem between reflected spectres of a specific kind of trees and the reflected spectre of the shadows of trees. The results did not only remove the shadows of the trees, but it also removed the shadows of the objects, i.e. the shadows of buildings. As those were not in our interest this did not affect the objective of our study.

Applying Equation 2 to the image resulting from the SI process, the NDVI image was created (Figure 5(a)). It discriminates the vegetated area (very white colour) from the non-vegetated area (dark grey and black color). Next, a threshold equal to 0.41 was experimentally selected from the NDVI image (Figure 5(b)). Based on this threshold, urban land use, water bodies and any other objects were removed from the image by masking out the non-vegetated area. As a final result of this process, images were created that include the vegetation canopy, but are without urban objects, water areas, roads, and soils (Figure 5)(c).

The NDVI helps to distinguish between vegetated and nonvegetated land cover, but it fails to discriminate grass from trees. The reason is that the NDVI of a dense grass may have the same (or nearby) NDVI value as that of a tree crown. This is shown for SP01 in Figure 5(c). Having extracted the vegetation areas, they were further classified into grass and trees. These two classes can be distinguished by considering their textural characteristics. Figure 6(b) and (c) represent the images created by calculating the homogeneity and entropy features, respectively, from the image resulting at the previous stage. A threshold was next selected from this image based on the combination of homogeneity and entropy features. For instance, the homogeneity value of tree canopy decreased, whereas simultaneously the entropy value increased. Next, the non-tree canopy (shrub and grass/lawn land, etc.) was masked out from the whole image, whereas the tree canopy remained to be displayed (Figure 6(d)). The final step of the workflow as shown in Figure 3 resulted in creating an image that displayed tree crowns only, which then turned out to be the so called IO. 


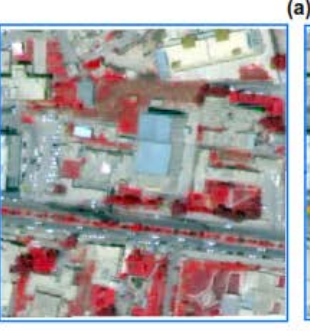

(a)
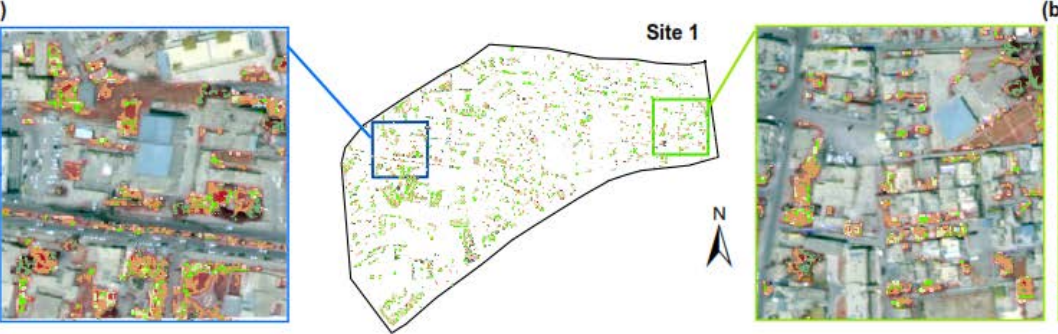

(b)
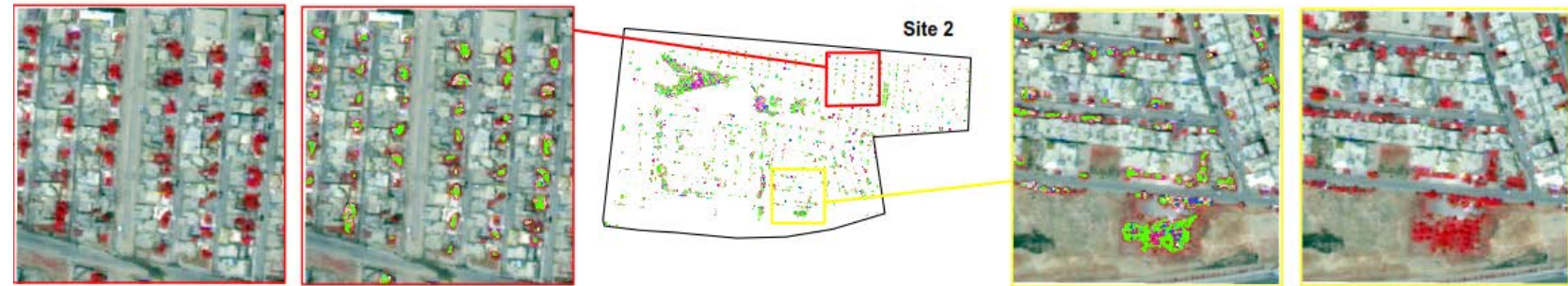

(d)

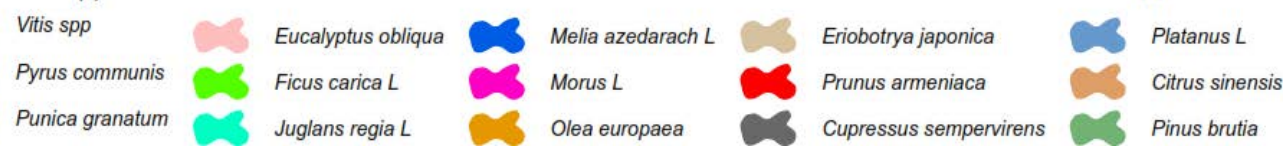

Figure 7: Classification map of all tree species in the study sites. (a) Sample 1 (SP01),

(b) Sample 2 (SP02), (c) Sample 3 (SP03), (d) Sample 4 (SP04).

Next, the IOs on the image were classified into the 15 different tree species. For that purpose, the three different classification algorithms (ML, NN, SVM) were used. The drawing training and validation samples (IOs) were modified indoor using ArcGIS software (V. 10.1) after the IOs were created. This is achieved to ensure that only tree canopy objects were counted for the classification. For the classification purpose, the training data were used with each classifier through utilizing ENVI software (V.4.7). Further, to evaluate the quality of tree species classification, an accuracy assessment was carried out. The conventional confusing matrix (Congalton and Green, 2009) was used for this purpose. The main criteria including the overall accuracy-OA, and $\kappa$-coefficient, were calculated for the two study sites. This procedure was implemented and evaluated for both groups (main and secondary trees) independently. Next, the best classifier was selected based upon these accuracy criteria (Table 3).

\begin{tabular}{|c|c|c|c|c|c|}
\hline Sites & Tree & Criteria & ML & NN & SVM \\
\hline \multirow{2}{*}{$\stackrel{\overbrace =}{\oplus}$} & Main & $\begin{array}{l}\mathrm{OA}(\%) \\
\kappa \text {-coefficient }\end{array}$ & $\begin{array}{l}52.23 \\
0.43 \\
\end{array}$ & $\begin{array}{l}46.06 \\
0.31\end{array}$ & $\begin{array}{l}73.57 \\
0.67\end{array}$ \\
\hline & Secondary & $\begin{array}{l}\text { OA(\%) } \\
\kappa \text {-coefficient }\end{array}$ & $\begin{array}{l}55.92 \\
0.49\end{array}$ & $\begin{array}{l}37.18 \\
0.24\end{array}$ & $\begin{array}{l}60.93 \\
0.57\end{array}$ \\
\hline \multirow{2}{*}{ 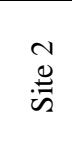 } & Main & $\begin{array}{l}\text { OA(\%) } \\
\kappa \text {-coefficient }\end{array}$ & $\begin{array}{l}73.80 \\
0.59\end{array}$ & $\begin{array}{l}82.00 \\
0.67\end{array}$ & $\begin{array}{l}88.92 \\
0.75\end{array}$ \\
\hline & Secondary & $\begin{array}{l}\text { OA(\%) } \\
\kappa \text {-coefficient }\end{array}$ & $\begin{array}{l}58.81 \\
0.53\end{array}$ & $\begin{array}{l}55.72 \\
0.47\end{array}$ & $\begin{array}{l}67.12 \\
0.66\end{array}$ \\
\hline
\end{tabular}

Table 3: The resulting classification accuracy, after implementing three classifiers for main and secondary trees.

The highest accuracy was obtained for both the main and the secondary group when using SVM (Table 3). The overall accuracy of the main and the secondary trees at Site 1 equals $73.57 \%$ and $60.93 \%$, with a $\kappa$-coefficient equal to 0.67 and 0.57 , respectively. Meanwhile, the resulting overall accuracy of the main and secondary trees at Site 2 equals $88.92 \%$ and $67.12 \%$ with a $\kappa$-coefficient equal to 0.75 and 0.66 , respectively. These results confirm the better performance of SVM than other classifiers as also reported in (Nitze et al., 2012), particularly with respect to small training sample sizes (Shao and Lunetta, 2012). Therefore, the SVM was adapted for the further steps in creating a tree species map. Our resulted accuracy assessment indicates a good result; based on comparing the results of this study with the results of the other recent studies. For instance, Pu and Landry (2012) classified and mapped seven tree species using WV-2, and found an overall accuracy of $62 \%$ with a $\kappa$-coefficient equal to 0.54 . Therefore, adding to the efficiency of WV-2 imagery in classifying individual trees, the methodology used in this study had a substantial role in increasing the accuracy of the classification. We further note that the accuracy may increase by integrating other variables within the methodology. For example, including other vegetation indices and composite texture measurements as extra contributing features during classification might further increase the classification accuracy. This is specially will be effective for diagnosing medium-height bushes which are often found in urban areas, and hence process them.

Figure 7 represents the classified map of the main and secondary tree species resulting from the SVM classifier, as illustrated for the samples SP01, SP02, SP03, and SP04. We notice that all other land types, e.g. buildings and streets, were not considered during classification. This indicates that our procedure as reported in Figure 3 of identifying the tree crown was successful.

\section{CONCLUSIONS}

The automatic extraction of features like tree crowns from VHR images and determination of their classes requires field validation, which is time consuming and may be ineffective for large areas with sparse tree coverage. In this study fifteen tree species were identified and mapped in an urban area of the city of Duhok. This is accomplished using VHR WV-2 imagery and includes application of a novel methodology to 
serve the objective of study. The study leads to the following conclusions:

1. Fifteen tree species were identified and mapped at a satisfactory accuracy in urban areas in the city of Duhok, Kurdistan Region of Iraq.

2. The SVM classifier gave more realistic result among three other supervised classifiers.

3. Given the presented method and results in this study, our approach can be applied in classifying and mapping different kinds of urban trees in other parts of the world as well.

\section{REFERENCES}

Ahmed, S.A., Dey, S., Sarma, K.K., 2011. Image texture classification using Artificial Neural Network (ANN), 2nd National Conference on Emerging Trends and Applications in Computer Science (NCETACS), pp. 1-4.

Ardila, J.P., Bijker, W., Tolpekin, V.A., Stein, A., 2012. Quantification of crown changes and change uncertainty of trees in an urban environment. ISPRS Journal of Photogrammetry and Remote Sensing, 74(0), pp. 41-55.

Ardila, J.P., Tolpekin, V.A., Bijker, W., Stein, A., 2011. Markov-random-field-based super-resolution mapping for identification of urban trees in VHR images. ISPRS Journal of Photogrammetry and Remote Sensing, 66(6), pp. 762-775.

Belgiu, M., Drăguţ, L., Strobl, J., 2014. Quantitative evaluation of variations in rule-based classifications of land cover in urban neighbourhoods using WorldView-2 imagery. ISPRS Journal of Photogrammetry and Remote Sensing, 87(0), pp. 205-215.

Blaschke, T., 2010. Object based image analysis for remote sensing. ISPRS Journal of Photogrammetry and Remote Sensing, 65(1), pp. 2-16.

Congalton, R.G., 1988. A comparison of sampling schemes used in generating error matrices for assessing the accuracy of maps generated from remotely sensed data. Photogrammetric Engineering and Remote Sensing, 54593600.

Congalton, R.G., Green, K., 2009. Assessing the accuracy of remotely sensed data : principles and practices, 2nd ed. CRC Press/Taylor \& Francis, Boca Raton.

DigitalGlobe, 2009. The benefits of the 8 spectral bands of WorldView-2.

DigitalGlobe, 2012. https://www.digitalglobe.com.

Ferro, C.J.S., Warner, T.A., 2002. Scale and texture in digital image classification. Photogrammetric engineering and remote sensing, 68(1), pp. 51-63.

Haralick, R.M., Shanmugam, K., Dinstein, I.H., 1973. Textural Features for Image Classification. IEEE Transactions on Systems, Man and Cybernetics, SMC-3(6), pp. 610-621.
Kim, M., M., M., Warner, T.A., 2009. Forest type mapping using object-specific texture measures from multispectral Ikonos imagery: Segmentation Quality and image classification issues. Photogrammetric Engineering \& Remote Sensing, 75(7), pp. 819-829.

Marceau, D.J., Howarth, P.J., Dubois, J.M., Gratton, D.J., 1990. Evaluation Of The Grey-level Co-occurrence Matrix Method For Land-cover Classification Using Spot Imagery. IEEE Transactions on Geoscience and Remote Sensing, 28(4), pp. 513-519.

Melgani, F., Bruzzone, L., 2004. Classification of hyperspectral remote sensing images with support vector machines. IEEE Transactions on Geoscience and Remote Sensing, 42(8), pp. 1778-1790.

Nitze, I., Schulthess, U., Asche, H., 2012. Comparison of machine learning algorithms Random Forest, Artificial Neural Network and Support Vector Machine to Maximum Likelihood for supervised crop type classification, Fourth international conference on Geographic Object-Based Image Analysis (GEOBIA) Conference, Rio de Janeiro - Brazil, pp. 35-40.

Petropoulos, G.P., Vadrevu, K.P., Xanthopoulos, G., Karantounias, G., Scholze, M., 2010. A Comparison of Spectral Angle Mapper and Artificial Neural Network Classifiers Combined with Landsat TM Imagery Analysis for Obtaining Burnt Area Mapping. Sensors, 10(3), pp. 19671985.

Pu, R., Landry, S., 2012. A comparative analysis of high spatial resolution IKONOS and WorldView-2 imagery for mapping urban tree species. Remote Sensing of Environment, 124(0), pp. 516-533.

Pu, R., Landry, S., Yu, Q., 2011. Object-based urban detailed land cover classification with high spatial resolution IKONOS imagery. International Journal of Remote Sensing, 32(12), pp. 3285-3308.

Shao, Y., Lunetta, R.S., 2012. Comparison of support vector machine, neural network, and CART algorithms for the landcover classification using limited training data points. ISPRS Journal of Photogrammetry and Remote Sensing, 7078-87.

Song, C., 2005. Spectral mixture analysis for subpixel vegetation fractions in the urban environment: How to incorporate endmember variability? Remote Sensing of Environment, 95(2), pp. 248-263.

Tso, B., Mather, P.M., 2009. Classification methods for remotely sensed data, 2nd ed. CRC Press, Boca Raton.

Weng, Q., Lu, D., Schubring, J., 2004. Estimation of land surface temperature-vegetation abundance relationship for urban heat island studies. Remote Sensing of Environment, 89(4), pp. 467-483.

Yang, J., 2012. Urban forestry in challenging environments. Urban Forestry \& Urban Greening, 11(2), pp. 103-104. 